\title{
A gestão da educação em municípios do Pará a partir da adesão ao Plano de Ações Articuladas (PAR)
}

\author{
Dalva Valente Guimarães Gutierres \\ Odete Cruz Mendes \\ Universidade Federal do Pará
}

\section{Resumo}

O trabalho analisa as implicações do Plano de Ações Articuladas (PAR) para a gestão educacional em cinco municípios do Pará, na perspectiva da gestão democrática, que pressupõe participação e autonomia. Com base em análise documental e entrevistas semiestruturadas, analisaram-se a existência e o funcionamento de conselhos municipais e escolares, Plano Municipal de Educação e critérios para a escolha de diretor. O PAR pouco tem contribuído para a democratização da gestão da educação municipal dos municípios analisados, pois prevalece a prática da gestão centralizada e patrimonialista, mesclada com arranjos típicos da gestão gerencialista.

Palavras-chave: Plano de Ações Articuladas. Gestão Democrática. Conselhos Municipais de Educação.

\section{The management of education in Pará municipalities from joining the Articulated Action Plan (PAR)}

\section{Abstract}

The work examines the implications of Articulated Action Plan (PAR) to the educational administration in five municipalities of Pará, from the perspective of democratic management, which requires participation and autonomy. An analysis, based on documents and and semi structured interviews, was made on the existence and functioning of municipal and school boards, as well as the Municipal Education Plan and their criteria for the choice of director. PAR contributed little to the democratization of educational administration of analyzed municipalities, as there is predomination of the practice of centralized and patrimonial management, merged with typical arrangements of managerialist management.

Keywords: Articulated Action Plan. Democratic management. Municipal councils of education. 
A gestão da educação em municípios do Pará a partir da adesão ao Plano de Ações Articuladas (PAR)

\section{La gestión de la educación en los municipios de Pará de unirse al plan de acción articulado (PAR)}

\section{Resumen}

El trabajo examina las implicaciones del PAR para la gestión educativa en cinco municipios de Pará, en la perspectiva de la gestión democrática, que requiere la participación y la autonomía. Basado en el análisis de documentos y entrevistas semiestructuradas, analizado la existencia y el funcionamiento de los consejos municipales y escolares, el Plan Municipal de Educación y los criterios para la elección de director. El PAR ha contribuido poco a la democratización de la gestión de la educación municipal de los municipios analizados, como la práctica vigente de gestión centralizada y patrimonial, se fusionó con arreglos típicos de la gestión gerencial.

Palabras clave: Plan de acción articulado. Gestión democrática. Consejos Municipales de Educación.

\section{Introdução}

$\bigcirc$ presente artigo trata da gestão municipal decorrente do Plano de Ações Articuladas (PAR) em cinco municípios paraenses, como parte da pesquisa "Avaliação do Plano de Ações Articuladas (PAR): um estudo em municípios dos estados do Rio Grande do Norte, Pará e Minas Gerais no período de 2007 a 2011 " - integrada ao Observatório da Educação -, OBEDUC/ CAPES.

Com o objetivo de analisar as implicações da implementação do PAR referentes à gestão educacional nos municípios, analisam-se alguns dos indicadores da área 2 (dois) - gestão democrática-, considerando que os princípios de democratização da gestão precisam extrapolar o âmbito formal/legal assegurados desde a Constituição Federal de 1988, para promover a real cidadania. Para isso, é de fundamental importância a participação da comunidade no processo de planejamento, deliberação e fiscalização das políticas educacionais por meio dos conselhos de educação que forram produzidos no contexto dos anos de 1980.

No entanto, como consequência da crise capitalista, a partir da década de 1990, o estado é redefinido na perspectiva de recomposição das 
taxas de lucro do capital e passa a investir menos em políticas sociais (PERONI, 2003). Por meio do Plano Diretor de Reforma do Estado (PDRAE) de 1995, o governo propõe para o setor público a gestão gerencial, na "[...] busca de incrementos nos índices de produtividade dos sistemas públicos" (SOUZA; FARIA, 2004, p. 566). Assim, a política educacional do Estado brasileiro, a partir da década de 1990, "[...] aponta para o redimensionamento do sistema de ensino, através de novas formas de gerenciamento, com vistas ao aumento de sua produtividade" (CABRAL NETO; ALMEIDA, 2000, p. 37).

Fundo de Desenvolvimento da Escola (FUNDESCOLA), cujo projeto principal era o Plano de Desenvolvimento da Escola (PDE)', é um exemplo das iniciativas que tinham como objetivo "[...] introjetar na esfera pública as noções de eficiência, produtividade e racionalidade inerentes à lógica capitalista [...]" (OLIVEIRA, 2000, p. 331 ) ao se propor formar profissionais da educação, com "atributos gerenciais" (FONSECA; OLIVEIRA, 2009), com base no planejamento estratégico. Essa mesma lógica foi assimilada pelo PDE/Plano de Metas Compromisso Todos pela Educação, cuja "ferramenta" de operacionalização no âmbito dos estados e municípios vem sendo o PAR.

A complexidade das transformações nas políticas de gestão educacional no espaço nacional nos instigou a pesquisa sobre as implicações do PAR para a gestão educacional em cinco municípios paraenses, a partir da seguinte questão: Quais as implicações do PAR para a gestão da rede municipal de educação dos municípios de Altamira, Barcarena, Belém, Cametá e Castanhal?

artigo em pauta baseou-se em cinco indicadores 2 : 1) Existência e funcionamento de conselhos escolares; 2) Existência e funcionamento do Conselho Municipal de Educação; 3) Existência e funcionamento do Conselho Municipal de Alimentação Escolar; 4) Existência de Plano Municipal de Educação; e 5) Critérios para a escolha de diretor.

Como metodologia, adotou-se o estudo documental e entrevistas semiestruturadas. Foi analisado o Decreto-Lei n 6.094, de 24 de abril de 2007, que estabelece o Plano de Metas Compromisso Todos pela Educação; o documento "Orientações para elaboração do PAR dos municípios"; o Termo de Adesão ao PAR; as Leis orgânicas municipais, entre outros documentos. As entrevistas utilizadas foram realizadas no âmbito da pesquisa que originou o trabalho com os técnicos municipais responsáveis pela coordenação e/ou 
A gestão da educação em municípios do Pará a partir da adesão ao Plano de Ações Articuladas (PAR)

elaboração e monitoramento do PAR, identificados no texto como Técnicos da Educação e respectivo município.

$\bigcirc$ artigo está estruturado em duas partes. Na primeira, intitulada "O PDE/Plano de Metas Compromisso Todos pela Educação e o Plano de Ações Articuladas - PAR: Diretrizes e princípios de gestão", situa-se a formulação do PDE/Plano de Metas Compromisso Todos pela Educação e do PAR, destacando as diretrizes que podem oferecer pistas a respeito da concepção de gestão educacional subjacente a essa política educacional. Na segunda, intitulada "A Gestão Educacional em Altamira, Barcarena, Belém, Cametá e Castanhal, a partir do PAR", foi analisada a configuração da gestão educacional municipal, com base nos indicadores selecionados. Nas considerações finais, foi retomado o objetivo central que motivou o estudo e apresentados os resultados das análises para o conjunto de municípios da pesquisa.

Assim, teve início, pela análise das diretrizes e princípios de gestão, constantes no PDE/Plano de Metas Compromisso Todos pela Educação.

\section{PDE/Plano de Metas Compromisso Todos pela Educação e o PAR: 164 diretrizes e princípios de gestão}

Plano de Desenvolvimento da Educação (PDE) pode ser considerado "[...] a primeira grande iniciativa do ministro Fernando Haddad, buscando uma reorientação de rumo para a educação no governo Lula" (OLIVEIRA, 2011 , p. 328).

Formado por 28 diretrizes, o PDE/Plano de Metas Compromisso Todos pela Educação (PMCTE) se apresentou como um grande "guarda-chuva", que integrou, inicialmente, um conjunto de ações preexistentes no Ministério da Educação e, ainda, outras ações novas ou remodeladas, com foco na Educação Básica, Superior, Profissional, alfabetização e diversidade.

A política de educação e gestão propugnada pelo PDE expressa a correlação de forças e as contradições típicas da sociedade de classes, pois o "Estado, a gestão pública e, em especial, a educacional materializam-se em um determinado momento histórico com características específicas e são parte de um movimento histórico maior" (PERONI, 2012, p. 26). Por isso, mesmo que o PDE tenha sido anunciado pelo Ministério da Educação (MEC) como um Plano composto por um conjunto de ações e programas, cujos propósitos eram 
enfrentar os problemas da educação brasileira, elevar o desempenho escolar e, em consequência, efetivar a qualidade da educação, suas orientações sinalizam ambiguidades e incoerências com esses propósitos, visto que vem impregnado pela lógica da gestão gerencialista.

Ademais, o Plano de Metas Compromisso Todos pela Educação (PMCTE) tem origem, de acordo com Saviani (2007), no Movimento Todos pela Educação ${ }^{3}$, movimento que congrega a sociedade civil organizada e os gestores públicos, e é mantido por um aglomerado de grupos empresariais ${ }^{4}$, cujo Conselho de Governança é composto, majoritariamente, por pessoas ligadas ao mundo empresarial ${ }^{5}$.

Ao privilegiar o empresariado como interlocutor, o MEC desconsiderou as entidades educacionais, sindicais e acadêmicas no processo de elaboração do PMCTE e afastou "[...] outros interlocutores que há mais de duas décadas vêm participando dos diferentes fóruns de definição das políticas, tanto em nível do próprio Ministério, quanto da própria sociedade [...]" (FREITAS, 2007, p. 1).

PDE não ocorreu de forma simultânea e coletiva, pois "[...] os sujeitos foram sendo chamados, consultados e incorporados no decorrer da formulação e execução da política, sem constituir um processo efetivo de construção democrática" (CAMINI, 2011 1, p. 166). Dessa maneira, os municípios e estados não participaram das decisões acerca do Plano em si, tendo sido chamados apenas para aderir ao Plano e responsabilizar-se pelas metas preestabelecidas.

Com o PDE, o governo federal se propôs a efetivar o regime de colaboração, enfrentar a questão da qualidade da educação, modernizar a gestão educacional e promover um Sistema Nacional de Educação. Para tanto, o governo propôs assistência técnica e financeira aos entes federados e exigiu deles responsabilização (accountability) pelos resultados (ADRIÃO; GARCIA, 2008). O PAR6 é descrito na legislação como "[...] o conjunto articulado de ações, apoiado técnica ou financeiramente pelo Ministério da Educação, que visa ao cumprimento das metas do Compromisso e a observância das suas diretrizes" (BRASIL, 2007). Nessa perspectiva, a adesão de municípios e estados ao PAR se efetiva por meio de contrato de gestão ou Termo de Adesão Voluntária?. 
A gestão da educação em municípios do Pará a partir da adesão ao Plano de Ações Articuladas (PAR)

Para verificar o cumprimento das metas do Compromisso, o PDE propôs o Índice de Desenvolvimento da Educação (ldeb) ${ }^{8}$. Para a elaboração do PAR, o MEC criou o Sistema Integrado de Monitoramento Execução e Controle do Ministério da Educação (SIMEC), pelo qual disponibilizou aos entes federados um instrumento de diagnóstico chamado PAR Analítico, organizado em quatro dimensões: I. Gestão Educacional; II. Formação de Professores e Profissionais de Serviço e Apoio Escolar; III. Prática Pedagógica e Avaliação; e IV. Infraestrutura Física e Recursos Pedagógicos.

Além do diagnóstico da situação municipal, são previstas ações, subações, metas, prazos de execução e entidades responsáveis por sua execução, na perspectiva de que "[...] os alunos melhorem o seu desempenho na Prova Brasil e no IDEB" (SILVA, 2010, p. 68).

A regulação presente nas diretrizes do PDE, de maneira geral, reafirma a reforma educacional do Estado brasileiro que foi iniciada na década de 1990, em especial a relacionada aos eixos da gestão, da avaliação e do financiamento (ALVES; SILVA, 2009), pautadas em uma visão de educação como um bem privado (ARAÚjO, 2007).

No que se refere à gestão dos sistemas de ensino, o PMCTE prevê:

XVIII - fixar regras claras, considerados mérito e desempenho, para nomeação e exoneração de diretor de escola;

XIX - zelar pela transparência da gestão pública na área da educação, garantindo o funcionamento efetivo, autônomo e articulado dos conselhos de controle social;

XXII - promover a gestão participativa na rede de ensino;

XXIII - elaborar plano de educação e instalar Conselho de Educação, quando inexistente;

$X X V$ - fomentar e apoiar os conselhos escolares, envolvendo as famílias dos educandos, com as atribuições, dentre outras, de zelar pela manutenção da escola e pelo monitoramento das ações e consecução das metas do compromisso (BRASIL, 2007).

O inciso XVIII prevê a criação de critérios para o provimento do cargo de diretor escolar com base no mérito e no desempenho individual, o que pode The atribuir grande responsabilização pelo sucesso ou pelo fracasso da gestão. No entanto, a construção democrática da educação requer requisitos que vão 
além da competência técnica do diretor, incluindo processo eletivo tendo em vista a "[...] legitimidade política necessária ao desempenho de suas funções" (PARO, 2007, p. 81 ), e isto não é considerado no Decreto.

A participação e a descentralização são parte constitutiva do papel dos Conselhos educacionais tratados nos incisos XXII, XXIII e XXV e são premissas presentes em praticamente todos os discursos da reforma educacional, "constituindo um 'novo senso comum'" (MEDEIROS; LUCE, 2006, p. 19). Contudo, apesar de parecerem idênticas, as propostas de gestão democrática encerram diferentes concepções de mundo e "[...] antagonismos matizados por interesses e concepções políticas ou até locais e particulares" (MEDEIROS; LUCE, 2006, p. 19).

Mecanismos como o Conselho Escolar, o Conselho Municipal de Educação e o Conselho de Alimentação Escolar, podem, no âmbito das relações sociais capitalistas, tanto contribuir com a emancipação social quanto referendar práticas patrimonialistas e autoritárias nos sistemas e interior das escolas públicas, ou ainda potencializar a prática da gestão gerencial pelo controle dos resultados.

\section{A gestão educacional em Altamira, Barcarena, Belém, Cametá e Castanhal a partir da adesão ao PAR}

\section{Os municípios da pesquisa}

Os cinco municípios considerados como lócus deste estudo estão localizados em três mesorregiões do estado do Pará: Metropolitana (Barcarena, Belém e Castanhal), Sudoeste (Altamira) e Nordeste (Cametá). Essas localidades apresentam extensão territorial, população e situação econômica variada, conforme mostram os números da Tabela 1, a seguir: 
A gestão da educação em municípios do Pará a partir da adesão ao Plano de Ações Articuladas (PAR)

\section{Tabela 1}

Municípios por Extensão Territorial, População, PIB e PIB per capita

$\begin{array}{ccccc}\text { Municípios } & \begin{array}{c}\text { Extensão territo- } \\ \text { rial }\left(\mathrm{Km}^{2}\right)^{1}\end{array} & \begin{array}{c}\text { População } \\ (2010)^{2}\end{array} & \begin{array}{c}\text { PIB }(\text { valor em } \\ \text { Mil, 2011) }\end{array} & \begin{array}{c}\text { PIB per capita (R\$ } \\ 1,00,2011)^{3}\end{array} \\ \text { Altamira } & 159.533,255 & 105.030 & 724.228 & 6.895 \\ \text { Barcarena } & 1.310,588 & 99.800 & 3.550 .233 & 35.573 \\ \text { Belém } & 1.059,458 & 1.392 .031 & 17.987 .323 & 12.922 \\ \text { Cametá } & 3.081,367 & 120.904 & 378.309 & 3.129 \\ \text { Castanhal } & 1.028,889 & 173.096 & 1.449 .213 & 8.372\end{array}$

Fonte | IBGE

Nota 1: IBGE/CIDADES, 2010-2013

Nota 2: Censo 2010, IBGE

Nota 3: IDESP/SEPOF-2014

A capital do estado, Belém, concentra o maior número de habitantes (1.392.003) entre os cinco municípios pesquisados e o município de Altamira possui a maior extensão territorial do estado e do país, com quase 160.000 $\mathrm{Km}^{2}$. Apesar de o município de Belém apresentar o maior PIB entre os cinco municípios pesquisados, é o município de Barcarena que possui a maior renda por habitante do conjunto da amostra, apresentando a terceira maior renda per capita do estado do Pará no ano de 2011 (IDESP/SEPOF/PA, 2014).

Quanto aos indicadores sociais, considerando o total de 5.565 municípios brasileiros, Belém ocupa a $628^{a}$ posição em relação ao IDHM e, entre os cinco municípios da pesquisa, situa-se em primeiro lugar com índice de 0,746, considerado alto pelo PNUD. O município de Cametá apresenta a $4.696^{a}$ posição dentre os municípios brasileiros e o menor índice dentre os cinco municípios $(0,577)$, considerado baixo. Os demais apresentam nível médio. Quando se analisam as dimensões de maior impacto na composição do IDHM, observa-se que, em todos os municípios, a longevidade ocupa o primeiro lugar; a renda, o segundo lugar; e a educação, o terceiro, o que leva a concluir que há muito a avançar na educação nesses municípios.

Quando se trata dos aspectos relacionados à qualidade do ensino um dos objetivos principais do PAR - os resultados da avaliação institucional do Ensino Fundamental de $4^{\circ} / 5^{\circ}$ ano e de $8^{\circ} / 9^{\circ}$ ano, realizada por meio do IDEB nos municípios, revelam o seguinte quadro: 


\section{Tabela 2}

IDEB da Rede Municipal dos municípios da pesquisa 2007-201 1

\begin{tabular}{ccccccc} 
Município & \multicolumn{3}{c}{ Ensino Fundamental } \\
& 2007 & 2009 & 2011 & 2007 & 2009 & 2011 \\
& 4,3 & 4,7 & 4,8 & 4,0 & 4,1 & 4,4 \\
Altamira & 3,4 & 3,4 & 3,7 & 3,5 & 3,3 & 3,1 \\
Barcarena & $3,4{ }^{\circ}$ ano & série/9 ano \\
Belém & 3,4 & 3,9 & 4,4 & 3,2 & 3,5 & 3,7 \\
Cametá & 2,6 & 2,7 & 3,4 & 2,9 & 3,2 & 3,3 \\
Castanhal & 3,3 & 3,7 & 3,9 & 3,7 & 3,5 & 3,7
\end{tabular}

Fonte | INEP

Os municípios que alcançaram as metas do ldeb em todos os anos do período da pesquisa foram apenas dois: Altamira e Belém. Castanhal cumpriu as metas em relação à primeira etapa do Ensino Fundamental (4\% $/ 5^{\circ}$ ano), enquanto Barcarena e Cametá não a cumpriram em um dos três anos da série analisada.

Com base nos aspectos discutidos até aqui, será analisada a gestão educacional nos municípios.

\section{A gestão das redes municipais de ensino a partir da adesão ao PAR}

Os gestores municipais formalizaram a adesão ao PAR desde a sua primeira versão; por isso, já no ano de 2008, a maioria deles possuía o Termo de Adesão visto a seguir:

Tabela 3

Número e ano do Termo de Adesão ao PAR e gestores municipais

$\begin{array}{ccc}\begin{array}{c}\text { Municípios } \\ \text { Altamira }\end{array} & N^{\circ} \text { Termo de Adesão } & \text { Gestor do Período em análise } \\ \text { Barcarena } & N^{0} 26.023 / 2008 & \text { Odileida Maria de Souza Sampaio (PSDB) } \\ \text { Belém } & N^{0} 16.681 / 2008 & \text { Duciomar Gomes da Costa (PTB) } \\ \text { Cametá } & N^{0} 19.921 / 2008 & \text { José Waldoli Filgueira Valente (DEM) } \\ \text { Castanhal } & N^{0} 22.853 / 2009 & \text { Hélio Leite da Silva (PR) } \\ \text { Fonte I SIMEC. Altamira, Belém e Cametá 2008; Castanhal, 2009; Barcarena, } 2011 .\end{array}$


A gestão da educação em municípios do Pará a partir da adesão ao Plano de Ações Articuladas (PAR)

Processo de elaboração do PAR ocorreu de forma apressada na maioria dos municípios, sem muita discussão pela rede. Ou seja, mesmo nos casos em que o município tenha recebido assessoria direta do MEC, como foi o caso de Altamira, ou da UFPA, em todos eles o processo apresenta um traço comum: a falta de precisão do diagnóstico, a pressa na elaboração e a participação limitada da comunidade, como pode ser constatado nas afirmações de alguns entrevistados:

O Par 2007-20 11 teve uma elaboração muito atropelada. Às vésperas do prazo encerrar nós recebemos a presença de um técnico que buscou o secretário de educação e explicou sobre o PAR [...]. Então o PAR 2007-201 1 foi elaborado em dois dias (TÉCNICO DE EDUCAÇÃO DE CASTANHAL, 2015).

$\mathrm{Na}$ época, vinha o discurso de que quem fizesse viriam verbas para várias ações [...] E aí foi feito assim... tudo muito rápido... foi feito a toque de caixa. Ele [assessor técnico do MEC/UFPA] veio em dois dias. [...]Se sabia muito pouco o que era, [...] Foi pá pá pá, e nós fizemos praticamente nas coxas, na marra (TÉCNICO DE EDUCAÇÃO DE BARCARENA, 2015).

OPAR ele foi uma, uma exigência do MEC [...] pela falta de experiência da gente, é.... o PAR foi feito, não foi um..., não foi um retrato muito concreto da realidade, né [...] era confuso e complicado para a gente entender essa organização, esse sistema como o ministério pensou (TÉCNICO DE EDUCAÇÃ̃O DE BELÉM, 2015).

O diagnóstico da situação educacional informado pela equipe de elaboração do PAR de cada município, embora impreciso, conforme relato, balizou a pontuação para cada um dos indicadores selecionados neste estudo evidenciados na Tabela 4: 


\section{Tabela 4}

Pontuação dos Indicadores de Gestão Democrática nos municípios

$\begin{array}{cccccc}\text { Municípios } & \text { CE } & \text { CME } & \text { CAE } & \text { PME } & \text { CED } \\ \text { Altamira } & 4 & 1 & 2 & 2 & 3 \\ \text { Barcarena } & 4 & 1 & 4 & 1 & 1 \\ \text { Belém } & 3 & 4 & 4 & 1 & 3 \\ \text { Cametá } & 3 & 1 & 4 & 1 & * \\ \text { Castanhal } & 2 & 4 & 4 & 1 & 4\end{array}$

Fonte | MEC/SIMEC/2008/2009/201 1 .

Nota 1 | CE - Conselho Escolar; CME - Conselho Municipal de Educação; CAE - Conselho Municipal de Alimentação Escolar; PME - Plano Municipal de Educação; CED - Critérios para escolha de Diretores

Nota $2\left(^{*}\right) \mid$ Informação ausente no documento do MEC/SIMEC

\section{Existência e funcionamento dos Conselhos Escolares (CE)}

A avaliação do funcionamento desse indicador, nos municípios de Belém e Castanhal, recebeu pontuação 4, que expressa uma situação em que o CME está devidamente implementado, com regimento interno, escolha democrática dos conselheiros e é representado por todos os segmentos; além disso, afirma que o CME é atuante, zela pelo cumprimento das normas e auxilia a SME no planejamento municipal da educação, na distribuição de recursos e no acompanhamento e avaliação das ações educacionais. Isso fica claro no depoimento dos entrevistados:

[Sobre o CME] se puder dar uma nota 10, a minha nota é 10 porque é uma equipe muito qualificada, competente, excelente. Fazem o assessoramento na escola o tempo todo (TÉCNICO DE EDUCAÇÃO DE BELÉM, 2015).

[...] conselho possui 18 anos, então é um conselho que muito antes do PAR já vinha com as suas ações de normatizar, fiscalizar, regular. Criou-se um sistema municipal de educação muito antes de se pensar o Plano de Ações Articuladas (TÉCNICO DE EDUCAÇÃO DE CASTANHAL, 2015). 
A gestão da educação em municípios do Pará a partir da adesão ao Plano de Ações Articuladas (PAR)

Os demais municípios - Altamira, Barcarena e Cametá - receberam pontuação 1, que expressa quando não existe um CME implementado ou quando o CME existente é apenas formal. Em Altamira e Cametá, embora existissem leis aprovadas, os conselhos não funcionavam no período de 2007 a 2011 . No entanto, a aprovação do CME em Cametá ocorreu por meio da Lei $n^{\circ} 16$, de 6 de maio de 1998, que também definiu suas competências. Embora tais competências expressem princípios e premissas democráticas, sua composição conforma interesses contrários, pois o princípio da paridade dos membros não foi respeitado, visto que, dos cinco membros previstos na lei, três deles pertencem ao governo, caracterizando "[...] a distinção de espaços de poder político e dos direitos instituídos [... turvados pelas relações fisiológicas" (DANIEL, 1994, p. 25), que se circunscreve no âmbito do poder local. Esse fisiologismo político está enraizado na cultura da administração pública do município de Cametá, conforme demonstrado no estudo de Mendes (2005).

Os membros do CME foram, segundo a Técnica da SEMEC de Cametá, empossados às pressas, por exigência do MEC, mas o funcionamento deste não corresponde ao previsto na lei, considerada retrógada, necessitando ser alterada.

A lei do conselho Municipal de Educação já existe há muitos anos [...] ela é uma Lei muito retrógrada. Mas com a pressa da gente criar e atender à exigência também do MEC, então a gente decidiv efetivar, criar o conselho dentro desta Lei que está e o conselho já foi eleito e efetivado. [...] a proposta é sentar e rediscutir esta Lei (TÉCNICA DA SEMEC DE CAMETÁ 2, 2015).

Constatou-se que, em cinco dos quatro municípios analisados, havia Leis de criação de CME aprovadas no período da pesquisa, conforme demonstrado na tabela a seguir: 


\section{Tabela 5}

Ato legal, composição e competência do CME por município

\begin{tabular}{|c|c|c|c|}
\hline Municípios & Lei Municipal & Composição & Competência \\
\hline Altamira & Lei n 657 , de 18/12/1995 & 12 membros & Deliberativo, Fiscalizador \\
\hline Belém & $\begin{array}{l}\text { Lei n } 7.509 \text {, de 30/01/1991, } \\
\text { Lei n 7.587, de 10/09/1992. }\end{array}$ & 13 membros & $\begin{array}{l}\text { Consultivo, deliberativo, } \\
\text { fiscalizador, normativo }\end{array}$ \\
\hline Castanhal & $\begin{array}{l}\text { Lei n076, de 29/1 1/1992, } \\
\text { Lei n } 015 \text {, de 27/05/1999. }\end{array}$ & 8 membros & $\begin{array}{l}\text { Consultivo, deliberativo, } \\
\text { fiscalizador, normativo }\end{array}$ \\
\hline Cametá & Lei n 016, de 06/05/1998 & 5 membros & $\begin{array}{l}\text { Consultivo, deliberativo, } \\
\text { fiscalizador, normativo }\end{array}$ \\
\hline
\end{tabular}

Fonte | Secretaria Municipal de Educação dos municípios

Em Barcarena, no período de 2007 a 201 1, não havia lei de criação do CME, o que se deu somente em 2013, pela Lei no 2.115, de 2 de janeiro de 2013 , sendo que o CME começou a funcionar em 2014.

Em Altamira, a reinstalação do CME se deu em 6 de abril de 2010, após "[...] ação civil pública impetrada pelo Fórum Popular que exigia o funcionamento do CME" (SOUSA, 2015, p. 1 16). O envolvimento dos CME dos municípios com as metas do PAR é limitado. A exceção é apenas o município de Castanhal, onde ocorre importante interlocução com a sociedade civil por meio do CME que assumiu também a função de Comitê de acompanhamento do PAR.

\section{Existência e funcionamento do Conselho Municipal de Alimentação Escolar}

O Programa Nacional de Alimentação Escolar (PNAE) é o mais antigo programa do governo brasileiro na área de educação (BALABAN, 2006). Em 1994, com a Lei n 8.913, de 12 de julho, ocorre a descentralização dos recursos do Programa para os municípios por meio de convênios, exigindo-se a criação de conselhos de acompanhamento das ações realizadas pelos Estados, pelo Distrito Federal e pelos Municípios. A fim de garantir melhor controle social da execução do PNAE, a Lei n 1 1.947, de 16 de junho de 2009, redimensionou a composição do Conselho de Alimentação Escolar (CAE). 
A gestão da educação em municípios do Pará a partir da adesão ao Plano de Ações Articuladas (PAR)

Os municípios da pesquisa aprovaram leis de criação do seu CAE bem antes do PAR, pois, em todos eles, houve a municipalização da merenda escolar ainda na década de 1990,

\section{Tabela 6}

Legislação e composição do CAE nos municípios

\begin{tabular}{|c|c|}
\hline Municípios & Lei Municipal \\
\hline Altamira & Lei no 654/1995 e Lei n $1.474 / 2001$ \\
\hline Barcarena & Lei $n^{\circ} 1.909 / 1997$, Lei n 1.936/2000 e Lei n 2.084/2010 \\
\hline Belém & Lei $n^{\circ} 8.045$, de 15/01/2001 \\
\hline Cametá & Lei n $017 / 98$, de 06/05/1998, e Lei n 040/00, de $31 / 08 / 2000$ \\
\hline Castanhal & * \\
\hline
\end{tabular}

Fonte | Secretarias Municipais de Educação dos municípios.

Noła $\left(^{*}\right)$ | Não tivemos acesso à Lei Municipal do CAE de Castanhal

A composição do CAE dos municípios segue, em linhas gerais, o que está previsto na legislação federal. No caso de Belém, o CAE é composto por

1747 membros, dentre os quais estão representantes do governo e da sociedade civil organizada, conforme preconizado na Lei n 8.045 de 15 de janeiro de 2001.

Belém, Barcarena, Cametá e Castanhal receberam a pontuação máxima no PAR, ou seja, 4. Tal pontuação é atribuída quando o CAE é representado por todos os segmentos (conforme norma), mas também porque ele possui um regimento interno conhecido por todos /comunidade interna e externa), reúne-se regularmente, atua fiscalizando a aplicação dos recursos transferidos, zela pela qualidade dos produtos, acompanha desde a compra até a distribuição dos alimentos/produtos nas escolas, está atento às boas práticas sanitárias, de higiene e ao objetivo de formação de bons hábitos alimentares.

município de Altamira recebeu pontuação 2 nesse indicador, o que caracteriza uma situação contrária à descrita anteriormente, pois "[...] a representação [...] do CAE não é [era] ativa nas suas atribuições de conselheiros. As ações do nutricionista não são [eram] de tempo integral" (ALTAMIRA, 2008). O 
diagnóstico sugeria a necessidade de nova eleição, capacitação de conselheiros e divulgação do regimento.

município de Cametá, ainda que tenha recebido pontuação 4 nesse indicador, o funcionamento do CAE parece não compatível com tal avaliação, pelo que afirma o técnico entrevistado:

[...] a participação é boa, mas eu considero um ponto que é mais importante e que está sendo negativo, é a questão de acompanhar a licitação, a conta dos produtos para a merenda escolar. $[\ldots]$ então se o conselho estivesse ali, atuando, cobrando [...] às vezes o conselheiro não sabe o poder que ele tem (TÉCNICO DE EDUCAÇÃO DE CAMETÁ 2, 2015).

Segundo o técnico entrevistado, a participação dos conselheiros é boa, mas ainda limitada, pois os conselheiros têm pouca consciência do seu papel junto ao poder público.

Há de observar, no entanto, que, em todos os municípios analisados, são impostos limites à ação dos conselheiros, por parte do poder público, no que diz respeito aos processos de fiscalização, de acompanhamento, de execução dos recursos e de distribuição da merenda seja pela ausência de infraestrutura, seja por não propiciar capacitação para esses conselheiros, fatos que já foram constatados em estudos sobre o tema desenvolvidos por Duarte (2008), Jacobi (2008), Gouveia e Souza (2006), Valle (2008) e Souza (2006).

\section{Existência de Plano Municipal de Educação}

Os municípios de Belém, Barcarena, Castanhal e Cametá receberam pontuação 1 nesse item, o que equivale à situação de que "[...] ou não existe nenhuma forma de acompanhamento e avaliação das metas do PME, por parte da SME, ou previsão de implantação, ou, ainda, quando não existe um PME" (BRASIL, 2008).

Em decorrência desse diagnóstico, a elaboração do PME constava entre as ações do PAR 2007-2011 que foram previstas por esses municípios. Entretanto, apenas em Barcarena essa ação foi realizada, pois "[...] no segundo semestre de 2009 [...] o primeiro Plano Municipal foi elaborado 
A gestão da educação em municípios do Pará a partir da adesão ao Plano de Ações Articuladas (PAR)

e aprovado na câmara municipal" (TÉCNICO DE EDUCAÇÃO BARCARENA, 2015).

No caso de Belém, o Plano foi aprovado em 24 de junho de 2015 pela Lei n 9. 129. Em Cametá, a aprovação do PME se fez por meio da Lei $n^{\circ} 274$, de 3 de março de 2015. Em Castanhal, o plano começou a ser discutido desde o final de 2010 e foi aprovado no final de 2011 na câmara municipal com "[...] a apresentação para a comunidade em 2012" (TÉCNICO DE EDUCAÇÃO DE CASTANHAL, 2015).

município de Altamira foi o único a receber pontuação 2 nesse indicador, que expressa a situação em que "[...] existe um PME e um planejamento para implementação de programa para o acompanhamento e avaliação de suas metas, mas no planejamento não está prevista a criação de um conselho com participação de professores e gestores e de representantes da sociedade civil organizada" (ALTAMIRA, 2008), ou seja, o planejamento existia, mas não de forma participativa.

De fato, no período de vigência do primeiro PAR, a sistemática de gestão adotada em Altamira se baseava nas orientações do Instituto Ayrton Senna9, que trabalhava com o plano de metas, definido pelo próprio Instituto e por alguns técnicos no âmbito da Secretaria de Educação (GUTIERRES, 2010), sem que houvesse ampla participação na definição das metas educacionais.

\section{Critérios para a escolha de Diretor}

No município de Castanhal, verificou-se a pontuação 4 para o indicador de critérios para a escolha de diretores de escolas, o que significa que "existem critérios definidos e claros para a escolha da direção das escolas; que estes critérios consideram experiência educacional, mérito e desempenho e que são conhecidos por todos e publicados na forma de Lei, Decreto, Portaria ou Resolução" (CASTANHAL, 2009). Nesse município, a Lei Municipal n²4, de 30 de novembro de 2000, e a Lei Complementar n $n^{\circ} 12$, de 26 de abril de 2013, regulamentam a escolha para diretor, que ocorre mediante eleição direta. O técnico da secretaria de Educação entrevistado confirma a existência e o cumprimento de tais critérios: 
Nós temos algumas regras que são da direção, que é [são] as eleições diretas. E quando o quantitativo é inferior a 300 alunos, geralmente o poder executivo tem feito a indicação que the cabe. [...] existem alguns critérios de ser licenciado pleno, concursado [...]. Existe uma Lei municipal que trata disso. Antes nós tínhamos uma lista tríplice que era encaminhada ao executivo e lá ele ia dizer quem seria o diretor e vice (TÉCNICO DE EDUCAÇÃO DE CASTANHAL, 2015).

Os municípios de Altamira e Belém receberam pontuação 3, atribuída "[...] quando existem critérios definidos para escolha da direção das escolas; estes critérios consideram experiência educacional, mérito e desempenho, mas não são de conhecimento de todos e não existe uma publicação legal". No caso de Belém, a Lei n 7.722 , de 7 de julho de 1994, define os critérios para escolha de diretores de escolas, no Capítulo VI, art. 16, onde se lê:

Os Diretores de Escolas serão constituídos em duas fases integradas, sendo a primeira um processo seletivo técnico destinado a averiguar os conhecimentos relativos à competência formal implicada no projeto pedagógico próprio, e a segunda um processo eletivo do qual participarão docentes, técnicos e funcionários da escola, mais os respectivos pais dos alunos, sendo os votos paritários (BELÉM, 1994).

Os dois casos não geraram ações, pois foram considerados como situação satisfatória. $\bigcirc$ município de Barcarena recebeu pontuação 1, que equivale à situação de ausência de critérios para escolha da direção das escolas. Entretanto, o art. 170, da Lei Orgânica municipal, define que "As direções das escolas municipais, serão escolhidas, por eleição direta, elegendo-se uma lista tríplice, para posterior nomeação de um nome pelo Prefeito Municipal" (BARCARENA, 1989). Contraditoriamente, a Lei Municipal n 1.899, de 16 de outubro de 1996, - Estatuto do Magistério - define:

Art. $2^{\circ}$ : A valorização das atividades do magistério será assegurada:

[...] V. Pela organização da gestão democrática do ensino público municipal, através de eleição direta para diretores das escolas, através de lista tríplice a ser regulamentada em lei específica.

Art. 13. Os cargos em comissão de Diretor, Vice-Diretor e Secretário são de livre nomeação e exoneração do Chefe do Poder executivo (BARCARENA, 1996). 
A gestão da educação em municípios do Pará a partir da adesão ao Plano de Ações Articuladas (PAR)

É interessante destacar que o Estatuto prevê critérios para a escolha de diretores diferenciados e contraditórios entre si, tais como: eleição direta, lista tríplice e cargo comissionado. A Lei Complementar $n^{\circ} 33 / 2010^{10}$, que trata do Plano de Carreira, considera os cargos de diretor e vice-diretor como cargos eletivos. No entanto, segundo o técnico entrevistado "[...] não houve uma vontade política que tirasse isso [eleição de diretores] do papel" (TÉCNICO DE EDUCAÇÃO DE BARCARENA, 20151.

Não há informação no PAR sobre pontuação a respeito desse indicador para o município de Cametá. No entanto, o art. 159 da Lei Orgânica Municipal define que "[...] o regimento do Conselho de Educação do Município estabelecerá normas para eleição de diretor das escolas municipais, observados os princípios educacionais" (CAMETÁ, 1990). Contraditoriamente, a Lei $n^{\circ} 212^{11}$, de 12 de maio 2012, em seu art. $8^{\circ}$, determina que os cargos de Direção, Vice-Direção de Escola, Suporte Pedagógico e Secretário de Unidade Escolar são consideradas Funções Gratificadas, "[...] de livre nomeação e exoneração pelo Chefe do Executivo, desde que recaia em profissionais ocupantes de cargos efetivos e devidamente habilitados". Nesse sentido, a técnica de educação entrevistada relata que: "Em relação à rede, a prática é de

178 indicação. Pouco se leva em consideração que deveria aplicar o que garante o PCCR do município" (TÉCNICO DE EDUCAÇÃO DE CAMETÁ 1, 2015).

Em todos os municípios da pesquisa, constatou-se participação limitada da comunidade no processo de escolha dos diretores de escola, contrariando os princípios de gestão democrática do ensino público, presentes na CF/88 e na LDB, prevalecendo a indicação política.

\section{Considerações finais}

princípio constitucional da gestão democrática do ensino público conquistado por meio das lutas da década de 1980 em prol da criação de conselhos municipais, conselhos escolares, planos municipais elaborados de forma participativa, processos de escolha de diretores de forma mais democrática foi um passo importante no processo de materialização da democratização das relações de poder no âmbito dos sistemas e da escola.

Todavia, a redefinição do papel do estado nos anos de 1990, e, consequentemente, das orientações de gestão pública ressignificaram a lógica 
da gestão educacional que passou a se pautar pelos princípios da gestão gerencial, proposta no Plano de Reforma do Estado.

O PDE/Plano de Metas Compromisso Todos pela Educação, cujas diretrizes subsidiam as ações do PAR, é baseado em princípios como eficiência, produtividade e racionalidade, típicos do mundo empresarial. A ideia de produtivismo se materializa, entre outros aspectos, por meio do ldeb, que produz ranking entre as escolas e os sistemas, e, sem dúvida, induz à competitividade. No caso do Pará, a persistência das desigualdades de ordem econômica, cultural e social impele às desigualdades de condições educacionais.

Quanto às implicações do PAR para a gestão educacional nos municípios da pesquisa, os resultados apontam que:

a) A existência dos conselhos escolares nesses municípios é anterior ao PAR e, embora assumindo caráter protocolar e burocrático existem conselhos escolares desde o final da década de 1990, tendo sido ampliado em quase toda a rede. No entanto, sua dinâmica de funcionamento limita-se praticamente ao gerenciamento dos recursos do PDDE. Com a intensificação da descentralização de recursos por meio do PDE-Escola e do PDDE Interativo, o PAR vem redimensionando ainda mais a dinâmica de funcionamento desses conselhos, secundarizando esse espaço como tomada de decisão e de construção de autonomia no interior da escola pública.

b) Os Conselhos Municipais de Educação, ainda que existam em lei na quase totalidade dos municípios, apenas em Belém e em Castanhal esses órgãos funcionam. Contudo, de maneira geral, assumem o caráter cartorial de regulação burocrática da rede, ignorando o papel de interlocutor entre o poder público e a sociedade civil. A democratização das decisões no âmbito dos sistemas municipais, na maioria dos municípios analisados, parece bastante fragilizada pelo não funcionamento ou funcionamento parcial dos CME.

c) Em relação ao Conselho de Controle Social da Alimentação Escolar (CAE), embora quatro municípios - Belém, Barcarena, Cametá e Castanhal - tenham recebido pontuação máxima, o que poderia sinalizar funcionamento ótimo, o depoimento dos entrevistados denunciam precariedade no funcionamento destes em relação à: falta de infraestrutura para reuniões, falta de acesso às escolas do campo e, até mesmo, falta de formação que possibilite acompanhar a execução dos recursos e a fiscalizar o armazenamento e a distribuição dos produtos. 
A gestão da educação em municípios do Pará a partir da adesão ao Plano de Ações Articuladas (PAR)

d) Foi predominante a ausência do PME nos municípios - Belém, Barcarena, Castanhal e Cametá. Estes trabalhavam baseados no Plano Plurianual (PPA) ou em um Plano de Metas, como em Altamira, cuja elaboração era restrita aos técnicos da Secretaria de Educação.

e) A escolha de diretores de escolas públicas nos municípios é, entre os indicadores analisados, o ponto mais obscuro, pois, embora o quadro de pontuação nesse indicador revele que $60 \%$ dos municípios apresentaram pontuação entre 3 e 4, o que poderia significar uma situação ótima ou boa, a legislação que trata do assunto é confusa e sujeita a interpretações diversas, pela profusão de critérios contraditórios entre si. Em linhas gerais, o que prevalece são as indicações políticas, resultantes de decisões de "gabinete", refletindo resquícios da cultura política das oligarquias locais, cuja marca principal é a centralização do poder e a privatização dos espaços públicos em benefícios particulares. Dessa maneira, a avaliação da gestão a partir dos indicadores revela que, na maioria dos municípios, há persistência de gestão centralizada e burocrática, mesclada com arranjos típicos da gestão gerencialista com ênfase no controle de resultados.

Vale destacar como aspecto positivo o fato de o PAR vir possibilitando

180 às secretarias de educação uma ferramenta a mais não só para a identificação dos problemas de organização da rede, mas também para a retomada da discussão sobre a função social da escola. Espera-se que isso possa vir a ser feito de forma realmente democrática.

\section{Notas}

1 FUNDESCOLA integrava a política de financiamento do Banco Mundial para o desenvolvimento da gestão da escola básica brasileira e foi implementado nos estados das regiões Norte, Nordeste e Centro-Oeste do país, com duração prevista para 10 anos, com início em 1998 (FONSECA; OLIVEIRA, 2009).

2 Embora o PAR (2007-2011) contemple em sua totalidade 4 dimensões, 15 áreas e 52 indicadores, selecionamos, para análise neste texto, 5 dos 9 indicadores que compõem a área gestão democrática pertencente à dimensão gestão educacional.

3 Lançado no dia 6 de setembro de 2006, o MTPE trouxe a perspectiva de construir um grande projeto nacional para a melhoria da qualidade da educação brasileira.

4 Dentre os mantenedores constantes no site do MTPE destacam-se as fundações: Bradesco, Vale, Lemann, Itaú Social, Telefônica Vivo; os institutos: Unibanco, Camargo Correa, Península; os bancos: Santander, Gerdau, Itaú. Apresenta ainda como parceiros: o Instituto Ayrton Sena (IAS) e a Globo, dentre outros. 
5 Em 201 1, o conselho apresentava a seguinte composição: Presidente: Jorge Gerdau Johannpeter; Conselho de Governança: Ana Maria dos Santos Diniz (Grupo Pão de Açúcar), Antônio dos Santos Matias (Fundação Itaú Social), Beatriz Bier Johannpeter (Fundação Gerdau) Viviane Senna (Presidente do Instituto Ayrton Sena), dentre outros (SOUZA; CAETANO, 2013).

6 O PAR apresentou, até o momento, duas etapas: a primeira teve vigência de 2007 a 2011 e a segunda, de 2011 a 2014.

7 A Adesão Voluntária de cada ente federativo ao Compromisso consta no artigo $5^{\circ}$, do Decreto $n^{0}$ 6.094/2007

8 A criação do IDEB está prevista no artigo 3², do Decreto n 6.094/2007.

9 A parceria com o IAS iniciou em 2001 e desenvolveu o Programa Escola Campeã, de 2001 a 2004. Posteriormente o convênio foi renovado, passando a chamar-se Rede Vencer. Em 2013 foi interrompido.

10 Essa lei dispõe sobre o Plano de Cargos, Carreira e Remuneração dos Profissionais da Educação Escolar Básica do município de Barcarena e encontra-se com seus efeitos suspensos, desde 2014 , em função da Ação Direta de Inconstitucionalidade (ADI), impetrada pelo prefeito municipal.

11 Essa lei dispõe sobre a adequação da carreira da área de magistério e criação unificada do Plano de Cargos, Carreiras e Remuneração dos profissionais da educação básica do município de Cametá-Pa.

\section{Referências}

ADRIÃO, Theresa; GARCIA, Teise. Oferta educativa e responsabilização no PDE: o Plano de Ações Articuladas. Cadernos de Pesquisa, São Paulo, v. 38, p. 779-796, set./dez. 2008.

ALTAMIRA (PA). Lei Municipal n 654, de 6 de dezembro de 1995. Dispõe sobre a criação do Conselho de Alimentação Escolar e dá outras providências. Altamira (Pará), 1995 (Publicada no Painel da Prefeitura).

Lei Municipal $\mathbf{n}^{\circ}$ 657, de 18 de dezembro de 1995. Dispõe sobre a criação do Conselho Municipal de Educação e dá outras providências. Altamira (Pará), 1995 (Publicada no Painel da Prefeitura).

Lei $\mathbf{n}^{\circ}$ 1.474, de 17 de maio de 2001. Dispõe sobre reformulação da lei do Conselho Municipal de Alimentação Escolar e dá outras providencias. Altamira (Pará): 2001 (Publicada no Painel da Prefeitura).

ALVES, Miriam Fábia; SILVA, Andréia Ferreira da. Análise do PNE e do PDE: continuidades ou rupturas? In: DOURADO, Luiz Fernandes (Org.). Políticas e gestão da educação no Brasil: novos marcos regulatórios. São Paulo: Xamã, 2009. 
A gestão da educação em municípios do Pará a partir da adesão ao Plano de Ações Articuladas (PAR)

ARAÚJO, Luiz. Os fios condutores do PDE são antigos. Jornal de Políticas Educacionais, v. 1 , n. 2, p. 24-31, set. 2007. Disponível em: http:/www.redefinanciamento.ufpr.br/araujo2. pdf. Acesso em: 5 maio 2015.

BALABAN, Daniel Silva. A importância de conselhos de alimentação escola: o controle de políticas públicas sob a ótica da cidadania. In: SOUZA, Donaldo Bello (Org.). Acompanhamento e controle social da educação: fundos e programas federais e seus conselhos locais. São Paulo: Xamã, 2006.

BARCARENA (PA). Lei Orgânica Municipal de Barcarena. Barcarena (Pará): 1989. Disponível em: http://barcarena.pa.gov.br/files/Procuradoria/2015/LEl\%20 ORG\%C3\%82NICA\%20DO\%20MUNIC\%C3\%8DPIO\%20DE\%2OBARCARENA/lei_organica_do_municipio_de_barcarena.pdf. Acesso em: 27 fev. 2016.

Lei ${ }^{\circ}$ 1.909, de 22 de setembro de 1997. Dispõe sobre a criação do Conselho Municipal de Alimentação Escolar e dá outras providências. Documento publicado no painel da Prefeitura Municipal de Barcarena em setembro de 1997.

Lei $\mathbf{n}^{\circ} \mathbf{1 . 9 3 6}$, de 30 de agosto de 2000. Dispõe sobre a criação do Conselho Municipal de Alimentação Escolar e dá outras providências. Documento publicado no painel da Prefeitura Municipal de Barcarena em agosto de 2000.

Lei $\mathbf{n}^{\circ} \mathbf{2 . 0 8 4}$, de $\mathbf{3 0}$ de dezembro de $\mathbf{2 0 1 0}$. Altera a Lei n⿳ $1.936 / 2000$, que criou o conselho municipal de alimentação escolar - CAE e dá outras providências. Documento publicado no painel da Prefeitura Municipal de Barcarena em 30 de dezembro de 2010.

Lei $n^{\circ} 2.115$, de 2 de janeiro de 2013. Dispõe sobre a Instituição do Sistema Municipal de Ensino e a criação do Conselho Municipal de Educação do Município de Barcarena, e dá outras providências. Diário Oficial do Município, Barcarena (Pará), v. 13, $n^{\circ} 1,31$ jan. 2013.

Lei Municipal $\mathrm{n}^{\circ} \mathbf{1 . 8 9 9}$, de 16 de outubro de 1996. Dispõe sobre a organização das atividades do magistério do $1^{\circ}$ grau e outros graus de ensino, bem como estruturação das respectivas carreiras, e dá outras providências. Documento publicado no painel da Prefeitura Municipal de Barcarena em maio de 1996.

BELÉM. Lei $\mathbf{n}^{\circ}$ 7.722, de 7 de junho de 1994. Dispõe sobre o Sistema Municipal de Educação de Belém. Disponível em: http://cm-belem.jusbrasil.com.br/legislacao/582746/lei-772294. Acesso em: 4 jun. 2014. 
Lei n. ${ }^{\circ}$ 7.509, de 30 de janeiro de 1991. Cria o Conselho Municipal de Educação de Belém e dá outras providências. Diário Oficial do Município, Belém (Pará), nº 6.964, 14 fev. 1991.

Lei n 7.587, de 10 de setembro de 1992. Altera os dispositivos da lei n 7.509, de 30 de junho de 1991, que cria o conselho municipal de educação. Diário Oficial do Município, Belém (Pará), n 7.361, de 18/09/1992. Disponível em: http://cm-belem. jusbrasil.com.br/legislacao/585370/lei-7587-92. Acesso em: 27 fev. 2016.

Lei $\mathbf{n}^{\circ} \mathbf{8 . 0 4 5}$, de 15 de janeiro de 2001. Institui o novo Conselho de Alimentação Escolar - CAE e dá outras providências. Disponível em: http://www.belem.pa.gov.br/ semaj/app/Sistema/view_lei.php?lei=8045\&ano=2001\&tipo=1. Acesso em: 27 fev. 2016.

BRASIL. Presidência da República. Constituição da República Federativa do Brasil de 1988. Diário Oficial [da] Republica Federativa do Brasil, Poder Executivo, Brasília, 5 out. 1988, Seção 1, p. 1.

Emenda Constitucional n 19, de 04 de junho de 1998. Modifica o regime e dispõe sobre princípios e normas da Administração Pública, servidores e agentes políticos, controle de despesas e finanças públicas e custeio de atividades a cargo do Distrito Federal, e dá outras providências. Diário Oficial [da] Republica Federativa do Brasil, Poder Executivo, Brasília, 15 jun. 1998, Seção 1, p. 1-3.

Decreto-Lei $\mathbf{n}^{\circ}$ 6.094, de 24 de abril de 2007. Dispõe sobre implementação do Plano de Metas Compromisso Todos pela Educação, e dá outras providências. Disponível em: http://www.planalto.gov.br/ccivil_03/_ato2007010/2007/decreto/d6094.htm. Acesso em: 10 jul. 2015.

Lei $\mathbf{n}^{\circ}$ 9.394, de 20 de dezembro de 1996. Estabelece as Diretrizes e Bases da Educação Nacional. Disponível em: www.ufrpe.br/dowload. php?Endarquivo=noticias/4248_LDB.pdf Acesso em: 20 set. 2015.

Lei $\mathbf{n}^{\circ}$ 8.913, de 12 de julho de 1994. Dispõe sobre a Municipalização da Merenda Escolar. Disponível em http://www.planalto.gov.br/ccivil_03/LEIS/L8913.htm. Acesso em: 20 set. 2015.

O Plano de Desenvolvimento da Educação: razões, princípios e programas. Brasília, 2007. Disponível em http://portal.mec.gov.br/arquivos/pdf/pne.pdf. Acesso em: 20 set. 2015. 
A gestão da educação em municípios do Pará a partir da adesão ao Plano de Ações Articuladas (PAR)

Relatório Público do Município de Altamira do Estado do PA. Brasília, DF: MEC/ SIMEC, 2009. Disponível em:http://simec.mec.gov.br/cte/relatoriopublico/principal.php ? system $=$ cooperacao\&ordem=5\&inuid $=2049$ \&itrid $=2 \&$ est=Para\&mun=Altamira\&municod $=$ $1500602 \&$ estuf $=P A$

Relatório Público do Município de Barcarena do Estado do PA. Brasília, DF: MEC/ SIMEC, 2011 Disponível em: http://simec.mec.gov.br/cte/relatoriopublico/principal.php ? system=cooperacao\&ordem=5\&inuid=2332\&itrid=2\&est=Para\&mun=Barcarena\&municod $=1501303 \&$ estuf $=$ PA

Relatório Público do Município Belém do Estado do PA. Brasília, DF: MEC/SIMEC, 2008. Disponível em: http://simec.mec.gov.br/cte/relatoriopublico/principal.php? system $=$ indicador\&ordem=7\&inuid $=1625$ \&itrid $=2 \&$ \&t=PA\&mun=Belem\&municod $=1501402$ \&est uf=PA. Acesso em: 15 jan. 2015.

Relatório Público do Município Cametá do Estado do PA. Brasília, DF: MEC/ SIMEC, 2008. Disponível em: http://simec.mec.gov.br/cte/relatoriopublico/principal.php 2. system=indicador\&ordem=7\&inuid $=1625$ \&itrid=2\&est=PA\&mun=Belem\&municod $=15014$ O2\&estuf=PA. Acesso em: 15 jan. 2015.

Relatório Público do Município de Castanhal do Estado do PA. Brasília, DF: MEC/

SIMEC, 2008. Disponível em: hitp://simec.mec.gov.br/cte/relatoriopublico/principal.php ? system=cooperacao\&ordem $=5$ \&inuid $=2722 \& i t r i d=2 \& e s t=P a r a \&$ mun $=$ Castanhal\&municod $=1502400 \&$ estuf $=$ PA

Lei $\mathrm{n}^{\circ}$ 11.947, de 16 de junho de 2009. Dispõe sobre o atendimento da alimentação escolar e do Programa Dinheiro Direto na Escola aos alunos da educação básica; altera as Leis nos 10.880, de 9 de junho de 2004, 1 1.273, de 6 de fevereiro de 2006, 1 1.507, de 20 de julho de 2007; revoga dispositivos da Medida Provisória no 2. 178-36, de 24 de agosto de 2001, e a Lei no 8.913, de 12 de julho de 1994; e dá outras providências. Disponível em: http://www.planalto.gov.br/ccivil_03/_ato2007-2010/2009/ lei/l1 1947.htm. Acesso em: 15 out. 2015.

CABRAL NETO, Antonio; ALMEIDA, Maria Doninha de. Educação e gestão descentralizada: Conselho Diretor, Caixa Escolar, Projeto Político-Pedagógico. Revista em Aberto, Brasília, v. 17, n. 72, p. 35-46, 2000. Disponível em: http://emaberto.inep.gov.br/index.php/ emaberto/article/viewFile/1090/991. Acesso em: 12 set. 2015.

CAMETÁ. Lei $\mathbf{n}^{\circ}$ 16, de 6 de maio de 1998. Dispõe sobre a Criação do Conselho Municipal de Educação - CME e dá outras providências. Documento publicado no painel da Prefeitura Municipal de Cametá em maio de 1998. 


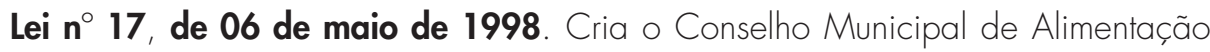

Escolar - CMAE e dá outras providências. Documento publicado no painel da Prefeitura Municipal de Cametá em maio de 1998.

Lei $\mathbf{n}^{\circ}$ 40, de 31 de agosto de 2000. Dispõe sobre a Criação do Conselho de Alimentação Escolar - CME e dá outras providências. Documento publicado no painel da Prefeitura Municipal de Cametá em agosto de 2000.

CAMINI, Lucia. PDE/Plano de Metas Compromisso Todos pela Educação: estratégias de participação e gestão na fase de formulação e implantação. In: PERONI, Vera; ROSSI, Alexandre (Org.). Políticas educacionais em tempos de redefiniç̃ões no papel do Estado: implicações para a democratização da educação. Porto Alegre: Editora UFPEL, 2011.

CASTANHAL. Lei Municipal $\mathbf{n}^{\circ} \mathbf{2 4}$, de $\mathbf{3 0}$ de novembro de $\mathbf{2 0 0 0}$. Altera dispositivos da Lei Municipal n²1/96 de 25 de novembro de 1996, que dispõe sobre a criação de Conselhos Escolares na rede municipal de ensino e dá outras providências. Documento publicado no Painel da Prefeitura Municipal de Castanhal em novembro de 1996.

Lei $\mathbf{n}^{\circ}$ 76, de 29 de setembro de 1992. Cria o Conselho Municipal de Educação e dá outras providencias. Documento publicado no Painel da Prefeitura Municipal de Castanhal em setembro de 1992.

Lei $\mathbf{n}^{\circ} \mathbf{0 1 2}$, de 26 de abril de 2013. Altera dispositivos da Lei Municipal 024 de 30 de novembro de 2000 sobre o processo de escolha dos gestores de unidades de ensino e dá outras providencias. Homologada pela Câmara Municipal de Castanhal no dia 07 de agosto de 2013. Documento publicado no Painel da Prefeitura Municipal de Castanhal em agosto de 2013.

DANIEL, Celso. Gestão local e participação da sociedade. Revista PÓLIS, São Paulo, n. 14, p. $21-42,1994$.

DUARTE, Marisa Ribeiro Teixeira. $\bigcirc$ Conceito de controle social e a vinculação de recursos da educação. In: REUNIÃO ANUAL DA ANPED, 29; 2006, Caxambu. Anais... Caxambu: Associação Nacional de Pós-Graduação e Pesquisa em Educação, 2006. Disponível em: http://www.anped.org.br/reunioes/29ra./trabalhos/gt05-2807/pdf. Acesso em: 15 dez. 2014.

FONSECA, Marília; OLIVEIRA, João Ferreira. A gestão escolar no contexto das recentes reformas educacionais brasileiras. Revista Brasileira de Política e Administração da Educação, Porto Alegre, v. 25, n. 2, p. 233-243, maio/ago. 2009. 
A gestão da educação em municípios do Pará a partir da adesão ao Plano de Ações Articuladas (PAR)

FREITAS, Helena. PDE: responsabilidades e desafios. [s.l.]: Confederação Nacional dos Trabalhadores em Educação, 2007. Disponível em: http://www.cnte.org.br/index. php/62 1 -retratos-da-escola/retratos-da-escola-numero-0 1 / 698-pde-responsabilidades-e-desafios. Acesso em: 29 jul. 2014.

GOUVEIA, Andréia Barbosa; SOUZA, Ângelo Ricardo. Revisitando a questão da natureza e da prática dos Conselhos de Acompanhamento e Controle Social (CACS) do FUNDEF no Estado do Paraná. In: SOUZA, Donaldo Bello de (Org.). Acompanhamento e controle social da educação: Fundos e programas federais e seus conselhos locais. São Paulo: Xamã, 2006.

GUTIERRES, Dalva Valente Guimarães. A municipalização do ensino no município de Altamira/PA e suas implicações para a democratização educacional. 2010. 367f. Tese (Doutorado em Educação) - Programa de Pós-Graduação em Educação, Universidade Federal do Rio Grande do Sul, Porto Alegre, 2010.

JACOBI, Pedro Roberto. Participação, cidadania e descentralização - Alcances e limites da engenharia institucional. In: SOUZA, Donaldo Bello de (Org.). Conselhos Municipais e controle social da educação: descentralização, participação e cidadania. São Paulo: Xamã, 2008.

186 MEDEIROS, Isabel Letícia Pedroso de; LUCE, Maria Beatriz. Gestão democrática na e da educação: concepções e vivências. In: LUCE, Maria Beatriz; MEDEIROS, Isabel Letícia Pedroso de (Org.). Gestão escolar democrática: concepções e vivências. Porto Alegre: UFRGS Editora, 2006.

MENDES, Odete da Cruz. A política de educação no município de Cametá: Análise sobre a proposta da escola CAÁ-MUTÁ. Escola Cidadã. 2005.[267f.] Dissertação ( Mestrado em Educação) - Programa de Pós-Graduação em Educação, Universidade Federal do Pará. Belém, 2005.

OLIVEIRA, Dalila Andrade (Org.). Educação básica: gestão do trabalho e da pobreza. Petrópolis: Vozes, 2000.

Das políticas de governo à política de estado: reflexões sobre a atual agenda educacional brasileira. Revista Educação \& Sociedade, Campinas, v. 32, n. 1 15, p. 323-337, abr./jun. 2011 . Disponível em: http://www.scielo.br/pdf/es/v32n 1 15/v32n $115 a 05$. pdf. Acesso em: 11 set. 2015.

PERONI, Vera Maria. Política educacional e papel do estado no Brasil dos anos 1990. São Paulo: Xamã, 2003. 
A gestão democrática da educação em tempos de parceria entre o público e o privado. Pro-Posições, Campinas, v. 23, n. 2, p. 19-31, maio/ago. 2012.

PARÁ. Lei Complementar n 06/91 de 27 de fevereiro de 1991. Dispõe sobre o funcionamento do Conselho Escolar dos Estabelecimentos de Ensino de $1^{\circ}$ e $2^{\circ}$ Graus da Rede Pública do Estado do Pará. Diário Oficial do Estado n²6.921 de 5 de mar. 1991.

Estatística Municipal de Altamira. Disponível em: http://www.idesp.pa.gov.br/ $\mathrm{pdf} /$ estatisticaMunicipal/pdf/Altamira.pdf. Acesso em 3 set. 2015.

Estatística Municipal de Barcarena. Disponível em: http://www.idesp.pa.gov.br/ pdf/estatisticaMunicipal/pdf/Barcarena.pdf. Acesso em 3 set. 2015.

Estatística Municipal de Belém. Disponível em: http://www.idesp.pa.gov.br/pdf/ estatisticaMunicipal/pdf/Belem.pdf. Acesso em 3 set. 2015.

Estatística Municipal de Cametá. Disponível em: http://www.idesp.pa.gov.br/ pdf/estatisticaMunicipal/pdf/Cameta.pdf. Acesso em: 3 set. 2015.

Estatística Municipal de Castanhal. Disponível em: http://www.idesp.pa.gov. br/pdf/estatisticaMunicipal/pdf/Castanhal.pdf. Acesso em: 3 set. 2015.

PARO, Vitor Henrique. $\bigcirc$ princípio da gestão escolar democrática no contexto da LDB. In: OLIVEIRA, Romualdo Portela de; ADRIÃO, Theresa (Org.). Gestão, financiamento e direito à educação: análise da Constituição Federal e da LDB. 3.ed. São Paulo: Xamã, 2007. p. 73-82.

PNUD. Atlas do desenvolvimento do Brasil. 2013. Disponível em: http://www.pnud.org. br/atlas/ranking/Ranking-IDHM-Municipios-2010.aspx. Acesso em: 3 set. 2014.

SAVIANI, Dermeval. O Plano de Desenvolvimento da Educação: análise do Projeto do MEC. Educação \& Sociedade, Campinas, v. 28, n. 100, p. 1231-1255, out. 2007 (Número Especiall)

SILVA, Andréia Ferreira da. Plano de Desenvolvimento da Educação (PDE), avaliação da educação básica e desempenho docente. Jornal de Políticas Educacionais, Paraná, v. 6, n. 8, p. 63-73, jul./dez. 2010. Disponível em: http://www.jpe.ufpr.br/n8_6.pdf. Acesso em: 10 jan. 2014.

SOUSA, Raimundo. O Plano de Ações Articuladas e a gestão educacional do município de Altamira - Pará. 2015. 192f. Dissertação (Mestrado em Educação) - Programa de PósGraduação em Educação, Universidade Federal do Pará, Belém, 2015. 
A gestão da educação em municípios do Pará a partir da adesão ao Plano de Ações Articuladas (PAR)

SOUZA, Donaldo Bello. Conselhos de acompanhamento e controle social: tendências municipais. In: SOUZA, Donaldo Bello (Org.). Acompanhamento e controle social da educação: fundos e programas federais e seus conselhos locais. São Paulo: Xamã, 2006.

SOUZA, Donaldo Bello de; FARIA, Lia Ciomar Macedo de. Políticas de financiamento da educação municipal no Brasil (1996-2002): das disposições legais equalizadoras às práticas político-institucionais excludentes. Ensaio: Avaliação e Políticas Públicas em Educação, Rio de Janeiro, v. 12, n. 42, p. 564-582, jan./mar. 2004.

TÉCNICO DE EDUCAÇÃO MUNICIPAL DE BARCARENA. Entrevista. Barcarena, 2 de setembro de 2015.

TÉCNICO DE EDUCAÇÃO MUNICIPAL DE BELÉM. Entrevista. Belém, 22 de junho de 2015.

TÉCNICO DE EDUCAÇÃO MUNICIPAL CAMETÁ 1. Entrevista. Cametá, 19 de agosto de 2015 .

TÉCNICO DE EDUCAÇÃO MUNICIPAL DE CAMETÁ 2. Entrevista. Cametá, 13 de agosto de 2015 .

$188 \quad 2015$

VALLE, Bertha de Borja Reis do. Controle social da Educação: Aspectos históricos e legais. In: SOUZA, Donaldo Bello de (Org.). Conselhos Municipais e controle social da educação: descentralização, participação e cidadania. São Paulo: Xamã, 2008.

Profa. Dra. Dalva Valente Guimarães Gutierres Universidade Federal do Pará | Belém Instituto de Ciências da Educação Programa de Pós-Graduação em Educação Grupo de Estudo e Pesquisa sobre Educação Superior | GEPES Grupo de Estudos em Gestão e Financiamento da Educação | GEFIN E-mail | dalva.valente@gmail.com 
Profa. Dra. Odete Cruz Mendes

Universidade Federal do Pará

Campus Universitário do Tocantins/Cametá Faculdade de Educação

Programa de Pós-Graduação em Educação e Cultura Grupo de Estudo e Pesquisa sobre Educação Superior | GEPES E-mail ocm@ufpa.br

Recebido 16 nov. 2015 Aceito 23 fev. 2016 